\title{
Atrial Fibrillation and Right Bundle Branch Block Complicating Coil Embolization of a Huge Pulmonary Arterio-Venous Malformation
}

\author{
Marco Colotto $^{1}$, Silvia Da Ros ${ }^{1}$, Giulia Barbarossa ${ }^{1}$, Alessandra Renzi ${ }^{1}$, Fabio Vinci ${ }^{1}$, \\ Paola Coletta ${ }^{1}$ and Filippo Maria Salvatori ${ }^{2}$
}

\begin{abstract}
Coil embolization is a safe therapy for pulmonary arterio-venous malformations (PAVMs). We report the case of a 72-year-old woman affected by hereditary hemorrhagic teleangectasia who experienced right bundle branch block and atrial fibrillation 36 hours after embolization of an extended PAVM. To our knowledge, this is the first case of such a complication of embolization of a pulmonary fistula, presumably due to an acute pressure overload on both the right atrium and ventricle. This case report suggests that, after embolization of extended pulmonary fistulas, patients should be carefully monitored for rhythm disturbance and new onset of intraventricular conduction defects.
\end{abstract}

Key words: coil embolization, pulmonary artero-venous malformation, hereditary hemorrhagic teleangectasia, atrial fibrillation, right bundle branch block

(Intern Med 50: 2983-2986, 2011)

(DOI: 10.2169/internalmedicine.50.6136)

\section{Introduction}

Pulmonary Arteriovenous Malformations (PAMVs) are not rare in patients affected by Hereditary Hemorrhagic Teleangectasia (HHT) (1). Metal coil embolization is considered a safe technique for the definitive treatment of PAMVs. The method was first introduced by Porstmann in 1977 and it has now completely replaced surgical resection as first line therapy (2-9). Complications associated with this procedure are generally rare and self-limited. The most frequent adverse events related to coil embolization are listed in the order of frequency in Table $1(3,5,10-13)$. The present article describes the first case of an HHT patient who, at 36 hours after coil embolization of an extended PAMV, experienced the onset of high ventricular rate paroxysmal atrial fibrillation (AF) and right bundle branch block (RBBB), which were both resolved spontaneously in a few days.

Case Report

A 72-year-old Caucasian HHT woman presented a huge PAVM, originating from both the superior and the inferior lobar branch of the left pulmonary artery with an extended draining vein (Fig. 1). The patient's clinical history was remarkable for dyspnoea on light exertion and recurrent nose bleeding episodes for many years. She denied symptoms such as palpitations, tachycardia, chest pain, or syncope. No history of atrial fibrillation or any kind of cardiac rhythm disturbance was reported by the patient. Physical examination showed labial, upper and lower extremities cyanosis, telangiectases in the skin of her face, fingertips and nasal mucosa. Arterial blood gas analysis showed a severe hypoxemia associated with normocapnia and reduced oxygen saturation $\left(\mathrm{SaO}_{2}\right)$ in room air (Table 2). The electrocardiogram showed sinus rhythm at a rate of 78 beats/minute. The echocardiogram did not show any pathological finding. Common extrapulmonary visceral arteriovenous malformations were ex-

\footnotetext{
${ }^{1}$ Department of Internal Medicine and Medical Specialties, "Sapienza" University-Policlinico Umberto I-Rome, Italy and ${ }^{2}$ Department of Radiological Sciences, "Sapienza” University-Policlinico Umberto I-Rome, Italy

Received for publication July 9, 2011; Accepted for publication September 4, 2011
}

Correspondence to Dr. Marco Colotto, m.colotto@policlinicoumberto1.it 
Table 1. Common Complications of Metal Coil Embolization of PAVMs (in Order of Frequency)

\begin{tabular}{l}
\hline - Chest Pain \\
- Pleurisy \\
- Hemothorax \\
- Pulmonary Infarct \\
- Deep Vein Thrombosis in the Catheter Introduction Site \\
- Device Embolization \\
- Stroke \\
- Severe Pulmonary Hypertension \\
\hline
\end{tabular}

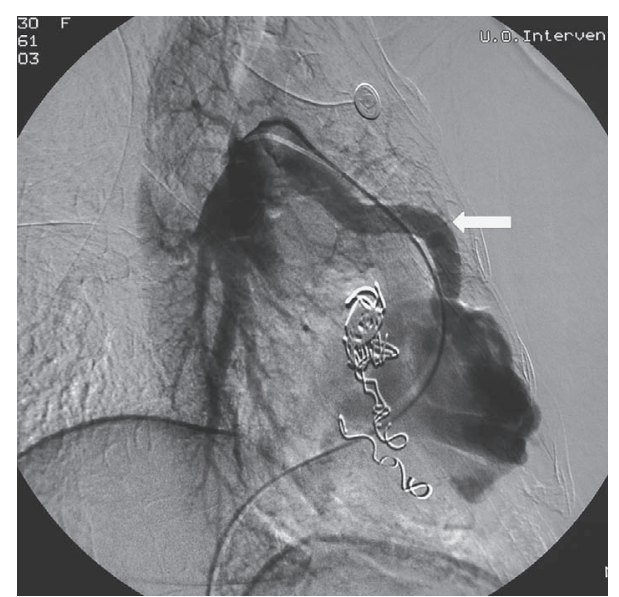

Figure 1. Huge pulmonary arteriovenous malformation originating from the left pulmonary artery with a large draining vein (arrow).

cluded by brain MRI, abdominal doppler ultrasonography and gastroscopy.

Embolization of the basal branches of the PAVM was performed using 7 and $9 \mathrm{~mm}$ diameter fibered platinum coils (Boston Scientific Cork-Ireland ${ }^{\circledR}$ ) for the smaller branch and $15 \mathrm{~mm}$ coil for the main branch. The procedure was complication free and resulted in complete exclusion of the arteriovenous malformation (Fig. 2).

Immediately after the treatment, markable relief of dyspnea, cyanosis and arterial gas analysis parameters was observed (Table 2). At 36 hours after the embolization the patient reported the onset of an irregular heart beat and shortness of breath. Upon physical examination she appeared restless and slightly tachypneic with a respiratory rate of 21 breaths per minute; neither cyanosis nor pathological findings were found, but an irregular heartbeat with a mean rate of 120 beats per minute was detected at physical examination; blood pressure was 130/90 $\mathrm{mmHg}$ in both arms.

The electrocardiogram revealed a new onset right bundle branch block (RBBB) associated with atrial fibrillation (AF) (Fig. 3) while the echocardiogram showed a new onset moderate tricuspid regurgitation with an estimated systolic pulmonary artery pressure (SPAP) of $42 \mathrm{mmHg}$. In order to rule out some common procedural complications associated with pressure overload such as hemothorax, pulmonary infarction and device embolization (Table 2) arterial gas
Table 2. Patient's Arterial Blood Gas Analysis before and after Metal Coil Embolization of PAVM

\begin{tabular}{ccc}
\hline & $\begin{array}{c}\text { Before PAVM } \\
\text { embolization }\end{array}$ & $\begin{array}{c}\text { After PAVM } \\
\text { embolization }\end{array}$ \\
\hline $\mathrm{pH}$ & 7,4 & 7,41 \\
$\mathrm{PaO}_{2}(\mathrm{mmHg})$ & 46 & 73 \\
$\mathrm{PaCO}_{2}(\mathrm{mmHg})$ & 42 & 41 \\
$\mathrm{HCO}_{3}(\mathrm{mmol} / \mathrm{L})$ & 28 & 26 \\
$\mathrm{SaO}_{2}(\%)$ & 83 & 95 \\
\hline
\end{tabular}

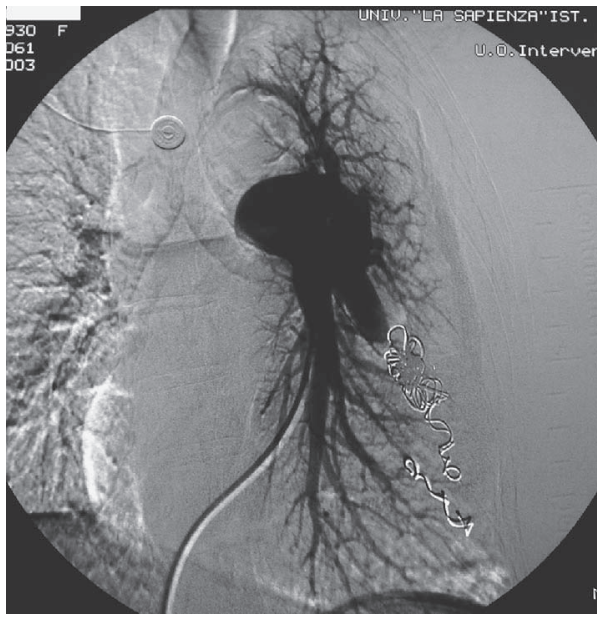

Figure 2. Angiographic control after embolization of the pulmonary arteriovenous malformation (PAVM) showing the complete exclusion of the fistula.

analysis, chest x-ray and blood tests including Troponin I, $\mathrm{LDH}, \mathrm{CPK}$, bilirubin, alanine and aspartate transaminase and d-dimers dosage, were performed. Arterial gas analysis confirmed the improvement of blood gases shown soon after coil embolization (Table 2). Blood tests were found within the normal range; no pathological findings were detected at chest X-ray (Table 1).

DC shock for the cardioversion of AF was proposed to the patient but she refused it. Diltiazem was started as an initial bolus of $20 \mathrm{mg}$ administered intravenously followed by continuous intravenous infusion of $10 \mathrm{mg} / \mathrm{h}$ for almost 20 hours. A decrease of ventricular rate (about $90 \mathrm{bpm}$ ) was achieved soon after administration of the Diltiazem bolus. Anticoagulation therapy was started with subcutaneous low molecular weight heparin (LMWH) (enoxaparin $1 \mathrm{mg} / \mathrm{kg}$ twice daily). At 24 hours after the onset of the AF sinus rhythm was restored; 36 hours later QRS on ECG evolved to a progressive narrowing (Fig. 4) and on the fifth day the electrocardiogram returned to as it was before the procedure (Fig. 5). The echocardiogram performed 1 week after the disappearance of the RBBB showed neither tricuspid regurgitation nor an increase of SPAP.

\section{Discussion and Conclusion}

Coil embolization of PAVM is generally considered a safe intervention with a low complication rate. In a literature search, only one other case report was found, which de- 


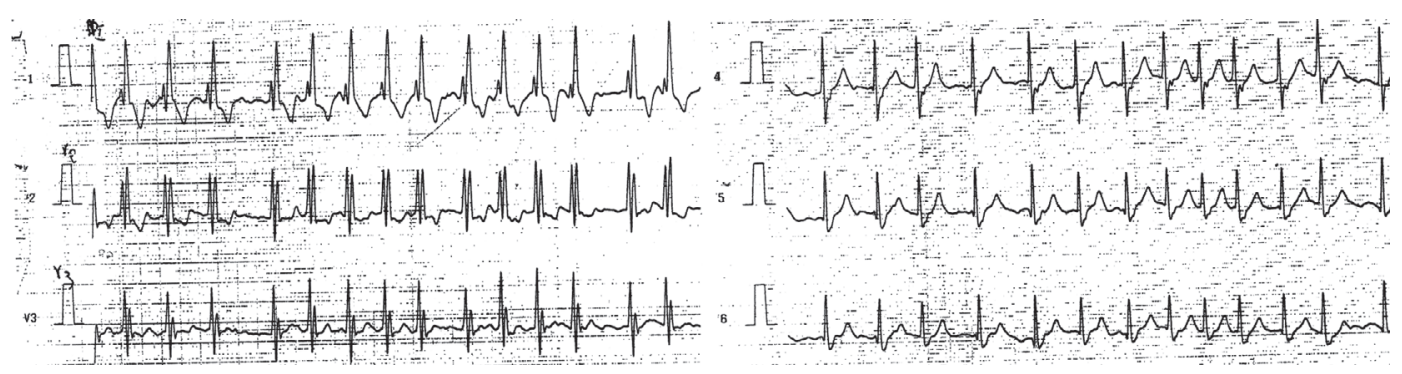

Figure 3. Electrocardiogram (ECG) (precordial leads), at 36 hours after intervention, showing atrial fibrillation and right bundle branch block (RBBB).

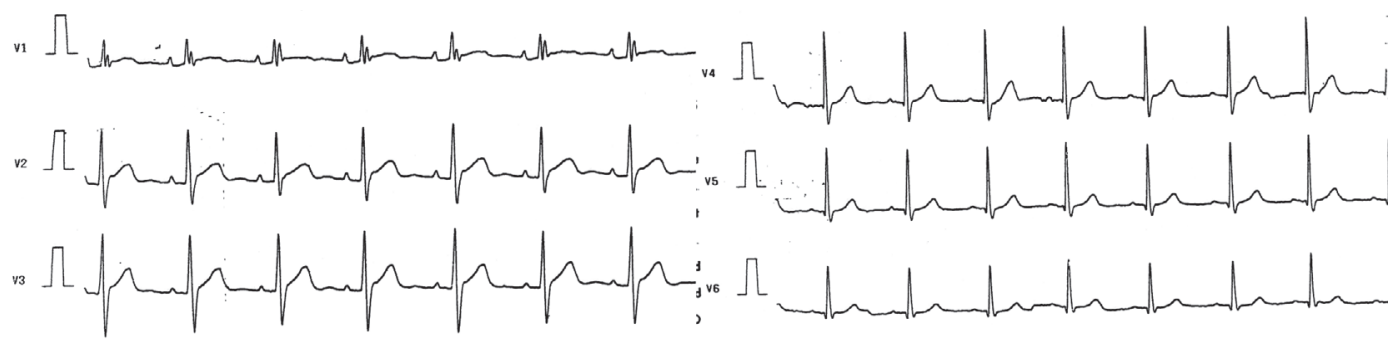

Figure 4. ECG (precordial leads), at 60 hours after intervention, showing restored sinus rhythm and RBBB persistence.

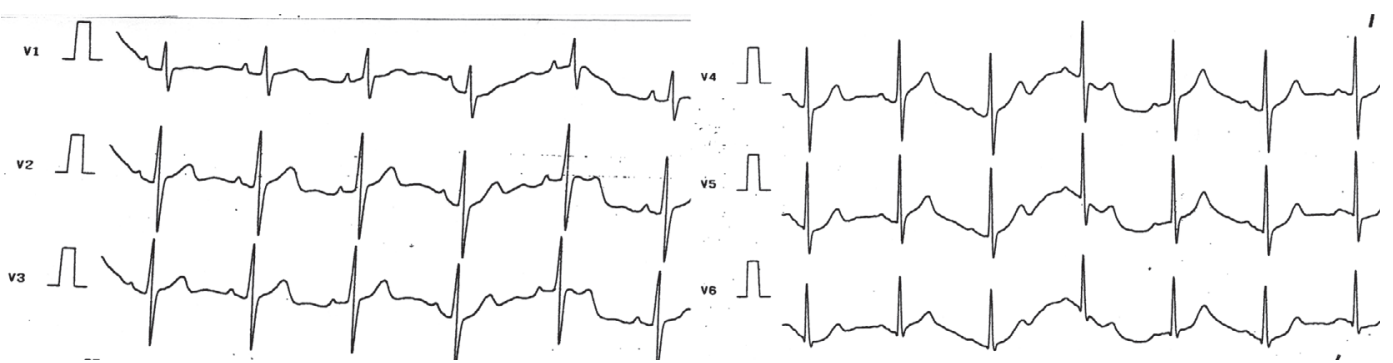

Figure 5. ECG (precordial leads), at 5 days after intervention, showing complete disappearance of RBBB.

scribed atrial fibrillation complicating coil embolization of a PAVM (14). However, the above-mentioned case concerned the coil embolization of a fistula from the circumflex artery to the pulmonary system. The authors of the report hypothesized that the onset of atrial fibrillation was provoked by the occlusion of a small branch supplying the sinus node. In our opinion, the present case needs a completely different physiopathological explanation: both atrial fibrillation and right bundle branch block could be interpreted as a consequence of the sudden change which occurred in pulmonary hemodynamics after the AVM closure. Indeed, the exclusion of a considerable reservoir for the blood flow coming from the left pulmonary artery may have caused an acute pressure overload on the right sections of the heart, thus leading to the onset of RBBB and AF.

A possible explanation of the prompt restoration of sinus rhythm (i.e. 24 hours) and the rapid disappearance of RBBB (i.e. few days) is that a progressive reduction of pressure overload in the right chambers of the heart could have occurred. In our opinion two possible mechanisms could ex- plain this reduction:

1) Diltiazem exerts a direct vasodilator effect on pulmonary circulation thus allowing a reduction in pulmonary pressure. Moreover, the therapy with diltiazem may have contributed to the restoration of sinus rhythm due to its activity on slow calcium channels as a class IV antiarrhythmic agent.

2) The new hemodynamic condition created by the occlusion of the huge arteriovenous fistula may have caused a progressive adaption of pulmonary microcirculation through the opening of capillary arteriovenous shunts, as it has already been demonstrated in the case of increase in pulmonary pressures (15).

In conclusion, although coil embolization is considered a very safe and effective intervention, this case suggests that after an occlusion of extended PAVMs through coil embolization, patients must be carefully monitored for the possible onset of rhythm disturbance and intra-ventricular conduction defect. 
The authors state that they have no Conflict of Interest (COI).

\section{References}

1. Cottin V, Chinet T, Lavolé A, et al. Pulmonary arteriovenous malformations in hereditary hemorrhagic telangiectasia: a series of 126 patients. Medicine (Baltimore) 86: 1-17, 2007.

2. Porstmann W. Therapeutic embolization of arteriovenous pulmonary fistula by catheter tecnique. In: Current Concept in Pediatric Radiology. Springer, Berlin, 1977: 23-31.

3. Gossage JR, Ghassan K. Pulmonary arteriovenous malformation. Am J Crit Care Med 158: 643-661, 1998.

4. Haitjema T, Overtoom TTC, Westermann CJJ, Lammers JWJ. Embolization of pulmonary arteriovenous malformations: results and follow up in 32 patients. Thorax 50: 719-723, 1995.

5. Dutton JAE, Jackson JE, Hughes JMB, et al. Pulmonary arteriovenous malformations: results of treatment with coil embolization in 53 patients. AJR 165: 1119-1125, 1995.

6. Remy-Jardin M, Wattinne L, Remy J. Transcatheter occlusion of pulmonary arterial circulation and collateral supply: failures, incidents, and complications. Radiology 180: 699-705, 1991.

7. Swanson KL, Prakash UB, Stanson AW. Pulmonary arteriovenous fistulas: Mayo Clinic experience, 1982-1997. Mayo Clin Proc 74: 671-680, 1999.

8. Wingen M, Gunther RW. Transcatheter embolization of pulmonary arteriovenous fistulas. Rofo 173: 606-611, 2001.

9. Magher JJ, Overtoom TTC, Blauw H, Lammers JWJ, Westermann CJJ. Embolotherapy of pulmonary arteriovenous malformations: long-term results in 112 patients. J Vasc Interv Radiol 15: 451456, 2004.

10. Puskas JD, Allen MS, Moncure AC, et al. Pulmonary arteriovenous malformations: therapeutic options. Ann Thorac Surg 56: 253-258, 1993.

11. Jackson JE, Whyte MKB, Allison DJ, Hughes JMB. Coil embolization of pulmonary arteriovenous malformations. Cor Vasa 32: 191-196, 1990.

12. Haitjema T, ten Berg JM, Overtoom TT, Ernst JM, Westermann CJ. Unusual complications after embolization of a pulmonary arteriovenous malformation. Chest 109: 1401-1404, 1996.

13. Uthaman B, Al-Qbandi M, Abushaban L, Rathinasamy J. Transcatheter closure of large pulmonary arteriovenous fistula including pulmonary artery to left atrial fistula with Amplatzer septal occluder. J Catheter Cardiovasc Interv 70: 422-428, 2007.

14. Pate GE, Webb JG, Carere RG. An unusual complication of coil embolization of a large coronary-pulmonary fistula. J Invasive Cardiol 15: 717-718, 2003.

15. Lovering AT, Romer LM, Haverkamp HC, et al. Intrapulmonary shunting and pulmonary gas exchange during normoxic and hypoxic exercise in healthy humans. J Appl Phys 5: 1418-1425, 2008 .

(C) 2011 The Japanese Society of Internal Medicine

http://www.naika.or.jp/imindex.html 